УДК 549.74

\title{
КАРБОНАТНЫЕ КОРЫ НА ФАСАДАХ ЗДАНИЙ И СООРУЖЕНИЙ ГОРОДА ТЮМЕНИ: РАЗНООБРАЗИЕ И ФАКТОРЫ ФОРМИРОВАНИЯ
}

\author{
Новоселов Андрей Андреевич', \\ mr.andreygeo@mail.ru \\ Константинов Александр Олегович², \\ konstantinov.alexandr72@gmail.com \\ 1 Тюменский государственный университет, \\ Россия, 625000, г. Тюмень, ул. Осипенко, 2 \\ 2 Тюменский индустриальный университет, \\ Россия, 625000, г. Тюмень, ул. Володарского, 56.
}

Актуальность работы. Карбонатные коры, наросты и выцветы, формирующиеся на фасадах различных зданий и сооружений в результате выщелачивания компонентов строительных материалов, таких как цемент, бетон, известняк, являются наиболее распространенными видами техногенного минералообразования в условиях городской среды. В отличие от непрочных сталактитов и сталагмитов, формирование которых наблюдается только в определенных условиях, подобные образования широко распространены. Развитие карбонатных кор, наростов и выцветов на фасадах зданий не только свидетельствует о процессах разрушения связующих компонентов строительных конструкций, но и оказывает негативное воздействие на эстетическую привлекательность объектов городской архитектуры. Натёчные образования кальцита заполняют микротрещины и неровности поверхностей облицовочных материалов, что приводит к интенсификации процессов разрушения и требует проведения дорогостоящих мероприятий по очистке фасадов. Исследования, посвященные изучению карбонатных новообразований на фасадах различных зданий и сооружений, немногочисленны.

Цель работы: выявление особенностей минерального состава, строения и возможных механизмов образования карбонатных кор и натеков, формирующихся на фасадах зданий и сооружений города Тюмени в различных условиях; определение факторов, способствующих данному явлению.

Методы: выявление и систематизация объектов городской архитектуры, подверженных процессам формирования карбонатных новообразований, поляризационная и инвертированная микроскопия в прозрачных шлифах, СЭМ-ЭДС, рентгеноструктурный анализ.

Результаты. Карбонатные коры и натеки существенно различаются по особенностям строения, минеральному составу и вероятным механизмам формирования в зависимости от конкретного местоположения. Четко разделяются коры, развивающиеся на вертикальных и горизонтальных поверхностях: первые - плоские, достаточно тонкие и имеют слоистую структуру, вторые плотные и характеризуются глобулярным строением. Формирование карбонатных новообразований происходит при значительном участии живых организмов, а процессы биогенного осаждения кальцита происходят синхронно с хемогенным. Четких связей между возрастом или местоположением конкретных объектов и интенсивностью формирования карбонатных кор не выявлено; соответственно данный процесс скорее обусловлен конструктивными особенностями конкретных сооружений и качеством строительных материалов.

\section{Ключевые слова:}

Карбонатные коры, карбонатные новообразования, техногенные спелеотермы, аутигенное минералообразование.

\section{Введение}

Строительные материалы в условиях городской среды подвергаются широкому спектру процессов физического и химического выветривания. Значительные перепады температур внутри и снаружи зданий и сооружений, частое переувлажнение при затруднённом испарении, различные виды механического воздействия приводят $\mathrm{k}$ постепенному разрушению исходной структуры и изменению свойств природных материалов [1-4]. Выщелачивание карбонатного материала цемента является одним из наиболее распространенных, заметных и потенциально опасных процессов, связанных с разрушением природных строительных материалов $[5,6]$. Растворение минеральных соединений, их последующая миграция и осаждение ведут к ухудшению связующих свойств цементного камня и ослаблению всей конструкции. Важным индикатором данного процесса является возникновение солевых кор, выцветов и натеков на фасадах зданий [6-9]. Подобные образования на поверхности облицовочных материалов в значительной степени ухудшают эстетическую привлекательность объектов городской инфраструктуры и требуют проведения дорогостоящих мероприятий по их удалению $[10,11]$. Формирование солевых кор негативно сказывается на облике города, сохранности памятников архитектурного и исторического наследия. Кроме того, в условиях урбанизированной территории процессы выветривания строительных материалов активизируются за счёт агрессивных химических соединений, поступающих в составе атмосферных аэрозолей, талых и дождевых вод $[12,13]$.

Изучение особенностей формирования карбонатных кор на фасадах зданий является важной теоретической и практической задачей, решение которой позволит выявить уязвимость конкрет- 
ных строительных материалов, установить зависимости между расположением и возрастом конкретных объектов с одной стороны и интенсивностью процессов выщелачивания с другой, выбрать наиболее подходящие методы при проведении мероприятий по очистке фасадов.

Целью данной работы является определение особенностей минерального состава, строения и возможных механизмов образования карбонатных кор, формирующихся на фасадах зданий и сооружений города Тюмени в различных условиях, а также выявление факторов, способствующих данному явлению.

\section{Объекты и методы исследований}

Объектами исследования послужили карбонатные коры, сформированные на фасадах различных объектов города Тюмени. Отобрано шесть образцов в течение 2016-2017 гг. Во всех рассматриваемых случаях фасады зданий и сооружений выполнены плитами из гранита рапакиви (рис. 1).

1. Нижний ярус набережной р. Туры (57 $9^{\circ} 38.84^{\prime \prime C}$; $65^{\circ} 31^{\prime} 51.45^{\prime \prime}$ ). Новообразования кальцита представлены массивными, толщиной до
1,5 см, карбонатными корами с ячеистой текстурой. Цвет новообразований варьируется от светло-бежевого до ржаво-бурого. Прочные коры и натеки формируются как на горизонтальных (образец 1-1), так и на вертикальных (образец 1-2) поверхностях.

2. Верхний ярус набережной р. Туры (57 9'49.89"C; $65^{\circ} 31^{\prime} 10.46$ "В). Новообразования представлены тонкими белыми и серыми корами, формирование которых происходит исключительно вдоль стыков гранитных плит ограды на верхнем уровне набережной вблизи крупной дороги.

3. Здание Департамента недропользования и экологии Тюленской области (57 9'14.62"C; $65^{\circ} 32^{\prime} 54.82^{\prime \prime}$ ). Новообразования представлены тонкими кипенно-белыми корами, развивающимися вдоль инженерных швов конструкции.

4. Здание ресторана «На Царской» $\left(57^{\circ} 9^{\prime} 34.39^{\prime \prime C}\right.$; $\left.65^{\circ} 31^{\prime} 46.52 " \mathrm{~B}\right)$. Новообразования представлены серовато-белыми, светло-бежевыми корами, формирующимися вдоль швов и трещин в гранитной плитке и слабо скреплёнными с поверхностью.

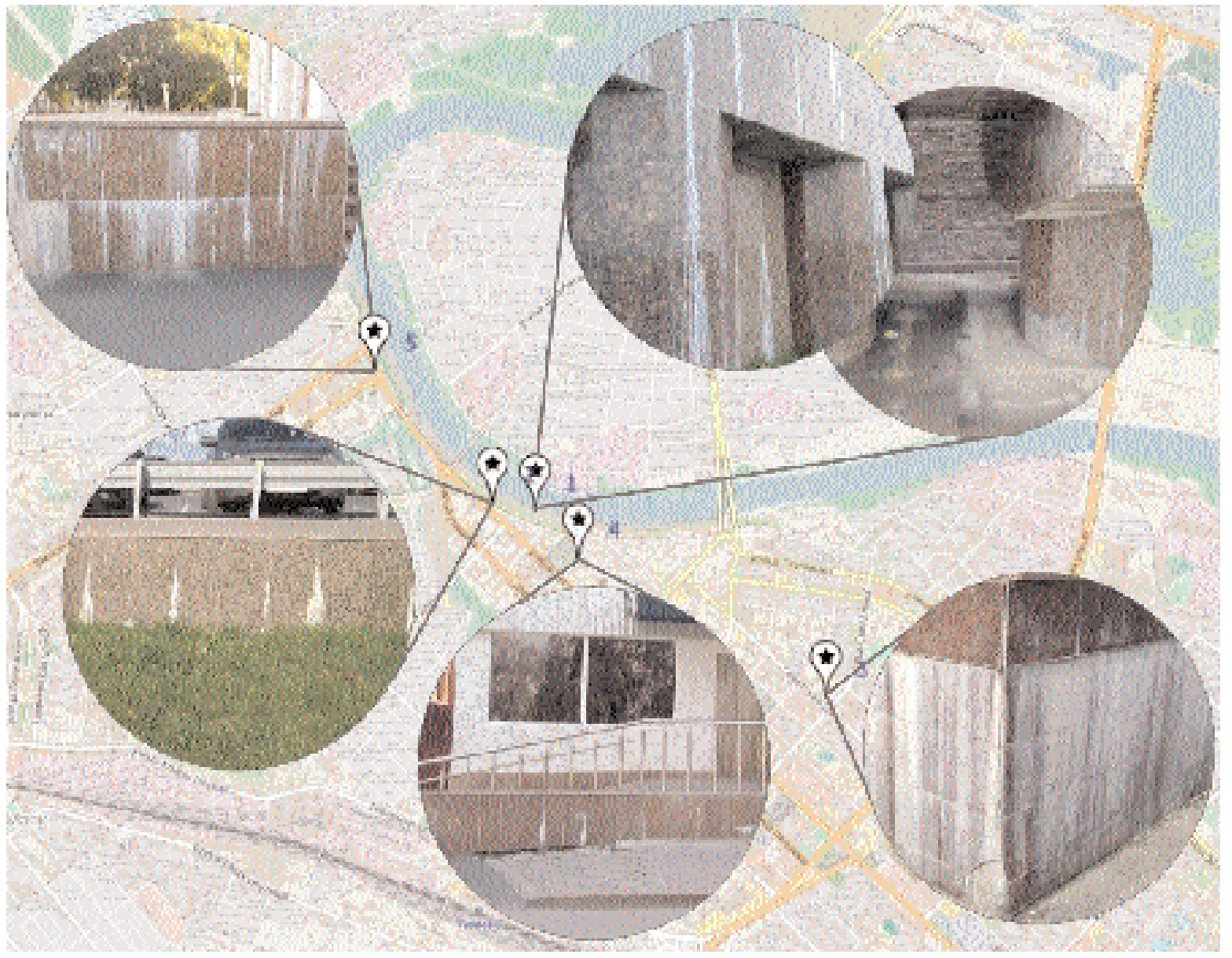

Pис.1. Местоположение объектов исследования на территории г. Тюмени: 1,2 - набережная $p$. Туры, 3 - Департамент недропользования и экологии Тюменской области; 4 - ресторан «На Царской», 5 - Тюменский индустриальный университет

Fig. 1. Sites background and location within the territory of Tyumen: 1,2 - Tura river embankment; 3 - Department of Subsoil Management and Ecology of the Tyumen Region; 4 - restaurant «Na Tsarskoy»; 5 - Tyumen Industrial University 
5. Здание Строительного института Тюменского индустриального университета $\left(57^{\circ} 10^{\prime} 0.38^{\prime \prime} \mathrm{C}\right.$; $\left.65^{\circ} 30^{\prime} 49.92 " \mathrm{~B}\right)$. Новообразования представлены корами кремового и белого цвета, формирующимися на крыльце здания. Фасад частично разрушен, на участках, где отсутствуют плиты, заметно, что натечные формы выступают на поверхности цементного камня, полностью срастаясь с ним, а цемент разрушен до арматурного скелета.

Изучение образцов проводилось в прозрачных шлифах с использованием поляризационного микроскопа Eclipse LV100POL «Nikon» (Япония) и инвертированного микроскопа отраженного света Axio Vert.A1 «Carl Zeiss» (Германия). Микроскопические и субмикроскопические исследования выполнены с помощью сканирующего электронного микроскопа TM3000 «Hitachi» (Япония) с приставкой для элементного анализа поверхности Quantax 70. Валовый минеральный состав карбонатных новообразований определен рентгеноструктурным методом в 000 «ЗапСибГЦ» (г. Тюмень) на порошковом рентгеновском дифрактометре ДРОН-2 «Буревестник» (Россия).

\section{Результаты и их обсуждение}

Во всех изученных новообразованиях основным минеральным компонентом является кальцит (таблица), содержание которого варьируется от $77,6 \%$ в корах на фасадах ресторана «На Царской» до 98,4% в корах на набережной.
Таблица. Минеральный состав карбонатных новообразований на фасадах зданий г. Тюмени

Table. $\quad$ Mineral composition of carbonate neoplasm on facades of buildings in Tyumen

\begin{tabular}{|c|c|c|c|c|c|c|c|}
\hline 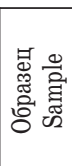 & 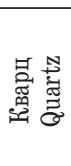 & 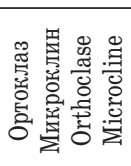 & 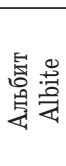 & 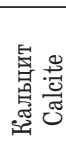 & 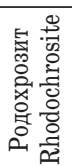 & 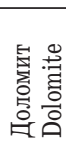 & 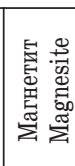 \\
\hline $1-1$ & 1,6 & 0,0 & 0,0 & 98,4 & 0,0 & 0,0 & 0,0 \\
\hline $1-2$ & 0,9 & 0,0 & 2,0 & 97,1 & 0,0 & 0,0 & 0,0 \\
\hline 2 & 9,6 & 0,0 & 1,3 & 86,2 & 0,0 & 2,9 & 0,0 \\
\hline 3 & 4,3 & 0,0 & 0,0 & 85,2 & 3,4 & 0,0 & 7,1 \\
\hline 4 & 3,8 & 6,1 & 9,6 & 77,6 & 0,8 & 2,1 & 0,0 \\
\hline 5 & 0,9 & 0,0 & 2,6 & 96,5 & 0,0 & 0,0 & 0,0 \\
\hline
\end{tabular}

Примечание. Нумерация образиов соответствует описанию в тексте.

Note. Numeration of samples corresponds to the description in the text.

Кроме того, в составе обнаружены кварц $(0,9-9,6 \%)$, альбит, ортоклаз, доломит, родохрозит, в единичных пробах магнетит (таблица). В целом наблюдается достаточно четкая зависимость между составом, морфологией, возрастом, цветом кор и соотношением кальцита и других компонентов. Наиболее высокие содержания кальцита характерны для новообразований на фасадах набережной Туры, где наблюдается наиболее высокие скорости современного минералообразования и коры формируются из перенасыщенных растворов. Наиболее высокие содержания кварца наблюдаются в новообразованиях вблизи крупных транспортных магистралей вследствие пыления.

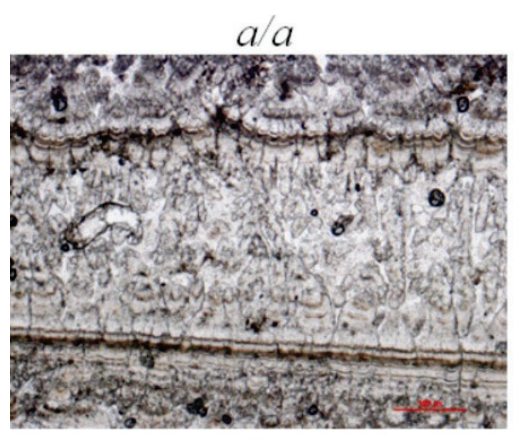

c/d

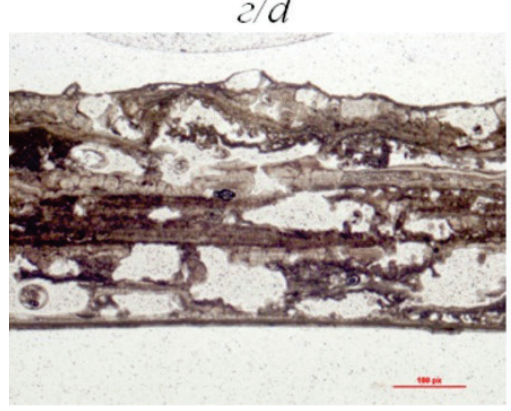

$6 / b$

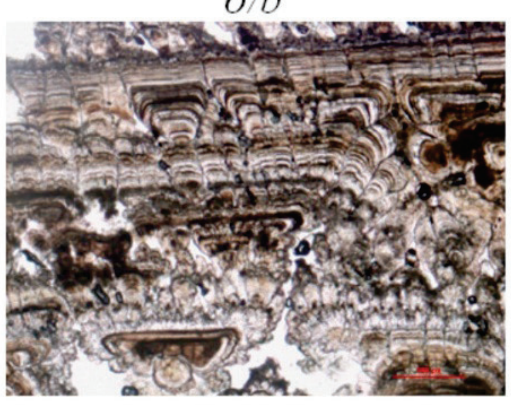

$\partial / e$

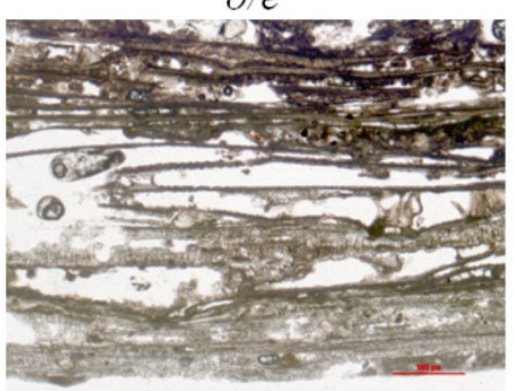

$B / C$

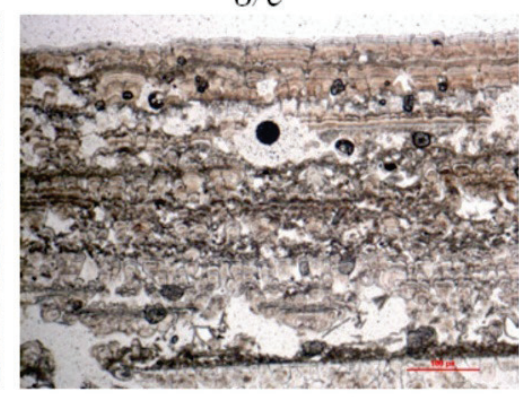

$e / f$

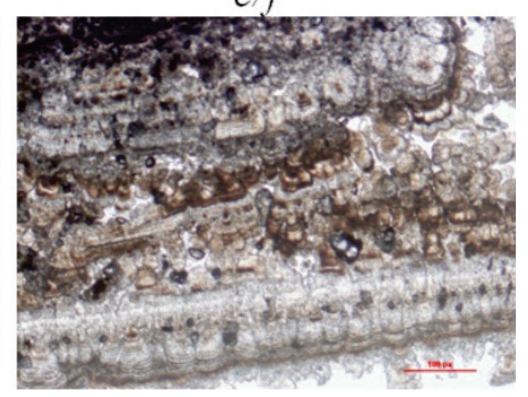

Pис. 2. Микростроение карбонатных новообразований на фасадах различных сооружений г. Тюлени (николи параллельны, увеличение в 4 раза): а) горизонтальные коры на нижнем ярусе набережной; б) вертикальные коры на верхнем ярусе набережной; в) верхний уровень набережной; г) фасад департамента; д) фасад ресторана; е) фасад университета

Fig. 2. Microstructure of carbonate neoplasms on the facades of various buildings in Tyumen (PPL, X4): a) horizontal crusts on the lower tier of the embankment; $b$ ) vertical crusts on the upper tier of the embankment; c) upper level of the embankment; $d$ ) facade of the department; e) facade of the restaurant; f) facade of the university 
Коры на фасадах нижних уровней набережной отличаются наибольшей толщиной среди всех изученных. Новообразования представляют собой последовательное чередование слоев, сложенных конкрециями и дендритовидными сростками микрокристаллов (рис. 2, $a$, б). При изучении в шлифах заметно, что материал, из которого формируются микрокристаллы и микросферы, неоднороден: в общем массиве заметны участки с признаками частичной перекристаллизации либо растворения. Полости между отдельными слоями практически отсутствуют, а межслойное пространство состоит из древовидных, направленных навстречу друг другу агрегатов, промежутки между которыми заполнены сросшимися сферолитами.

Новообразования, развивающиеся на верхних уровнях набережной, состоят из равных по толщине слоев, которые плотно прилегают друг к другу в месте крепления к поверхности гранитных плит (рис. 2, в) Наибольшие пустоты между слоями, составляющие карбонатные новообразования, приурочены к инженерным швам, где происходит наиболее интенсивное переотложение карбонатного материала. В таких полостях наблюдаются как древовидные ветвистые агрегаты, состоящие из удлиненных кристаллов со следами растворения, так и ассоциации концентрических образований.

Новообразования на фасадах здания Департамента недропользования и экологии (рис. 2, г) отличаются гладкой внешней поверхностью, в трещинах которой заметны небольшие кристаллы. Отдельные слои, составляющие новообразование, характеризуются приблизительно одинаковой толщиной и равноудалены друг от друга. В межслойном пространстве развиваются два типа кристаллов: первые - крупные ромбоэдрические образования, составляющие сноповидные агрегаты, которые впоследствии обрастают небольшими вторичными кристаллами и за счет этого принимают форму близкую к округлой. Вторые - мелкие изометричные микрокристаллы, которые образуют шарообразные ассоциации и нередко покрыты тонкими органическими пленками.

Новообразования на поверхностях крыльца ресторана "На Царской» являются самыми маломощными из всех изученных (рис. 2, Ә). Данные карбонатные коры состоят из большего количества тонких слоев, разделенных обилием небольших полостей. Необходимо отметить, что только вблизи поверхности наблюдаются заполненные микроконкрециями полости, что свидетельствует о малой интенсивности процессов минералообразования.

Наиболее неоднородные, состоящие из нескольких неравных по толщине слоев, коры формируются на фасадах здания строительного института (рис. $2, e$ ). Поверхности таких новообразований состоят из сглаженных ромбоэдрических кристаллов, а внутренние полости заполнены ассоциациями микрокристаллов. Также наблюдаются трещины, заполненные карбонатным материалом в виде сплошных, практически монолитных блоков с едва угадываемыми очертаниями уплощенных шестоватых кристаллов.

Все изученные коры характеризуются наличием четко выраженной осевой плоскости, относительно которой развиваются однонаправленные микрокристаллы разных конфигураций. Горизонтально нарастающие коры имеют более плотное строение, без полостей и с заметными следами вторичной перекристаллизации или, как минимум, неоднократного частичного растворения (рис. $3, a$ ).

Вертикально растущие образования имеют большое количество полостей, нарушающих однородность структуры (рис. 3, б). Как правило, в коpax наблюдается более 5-6 слоев, большая часть которых имеет примерно одну мощность. При этом заметны как более массивные, так и тонкие слои, что, вероятно, свидетельствует о неравномерности поступления материала. Данный факт позволяет предположить, что коры формируются в течение нескольких сезонов, а при благоприятных условиях, возможно, и лет [14].
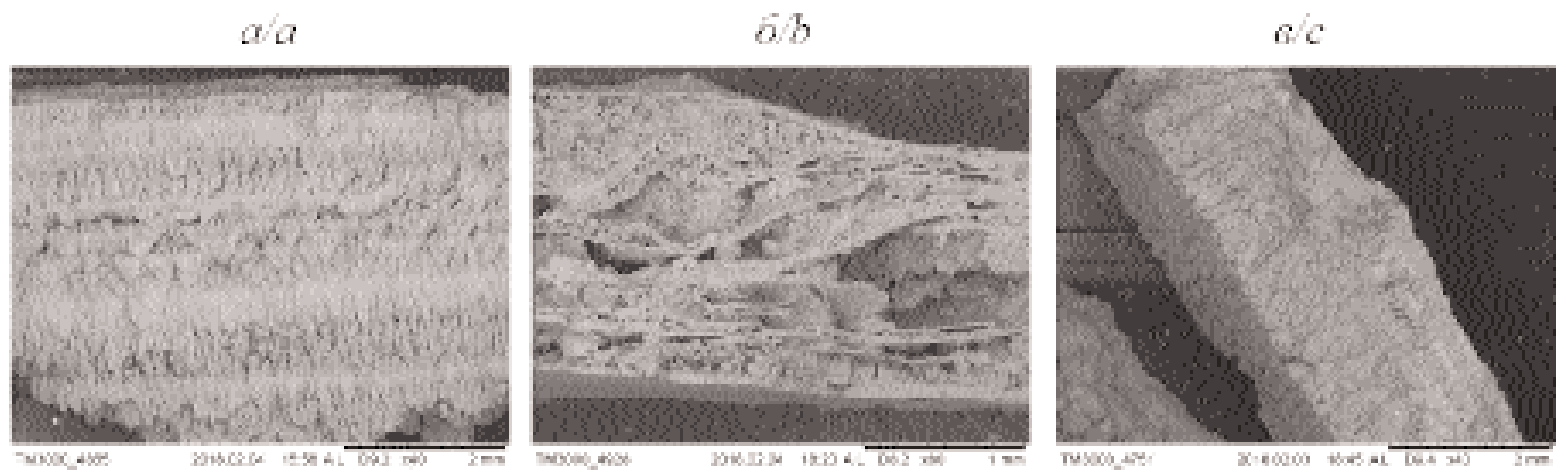

Pис. 3. Строение различных типов карбонатных кор, сформированных на фасадах различных сооружений г. Тюмени, выявленное при помощи сканирующей электронной микроскопии: а) плотные коры со следами вторичной перекристаллизации (Х120); б) слоистые коры с большим количеством полостей (X80); в ) столбчатые агрегаты, составляющие отдельные слои кор (X40)

Fig. 3. Structure of various types of carbonate cores formed on the facades of buildings in Tyumen, identified by SEM: a) dense cortex with traces of secondary recrystallization (X120); b) layered bark with a large number of cavities (X80); c) columnar aggregates, making up separate layers of cores (X40) 
Отдельные слои новообразований состоят из вытянутых субпараллельных столбчатых агрегатов, имеющих концентрическое строение (рис. 3, в). Практически в каждом из таких агрегатов в центре заметно отверстие, в котором нередко сохраняется гиф гриба, выступающий в качестве каркаса при развитии внутреннего пространства новообразования и во многом определяющий их морфологию и ориентацию $[15,16]$. От слоев, состоящих из столбчатых агрегатов, берут свое начало дендритовидные сростки микрокристаллов, тяготеющие к одной из поверхностей (рис. $4, a)$. Часто внутри полостей такие древовидные агрегаты срастаются $\mathrm{c}$ противоположно направленными на соседнем слое. На поверхности отдельных кристаллов нередко встречаются следы растворения. Пустоты новообразований в процессе роста постепенно заполняются разноразмерными преимущественно ромбическими кристаллами, а их ассоциации образуют форму близкую к сферической (рис. 4, б).

Иногда внутреннее строение карбонатных кор нарушают границы, на которых резко прерывается рост кристаллов, сменяясь следующей формацией с новой структурой. В единичных случаях на такой границе заметны прослои, обогащенные органическим веществом и механическими включениями. Но в большинстве случаев никаких видимых причин прерывания процесса кристаллизации нет, что свидетельствует о том, что вероятной причиной формирования именно таких границ является механическая очистка фасадов сооружений, после которой рост новообразований возобновляется.

Внешние поверхности натечных новообразований можно условно разделить на два типа. Первый тип - ровные, гладкие коры, на внешней стороне которых кристаллы кальцита практически полностью сглажены и не просматриваются даже при большом увеличении. Как правило, такие поверхности характерны для вертикально растущих кор. Второй тип - коры, поверхность которых имеет выраженный рельеф, а поверхность состоит из крупных ассоциаций микрокристаллов, имеющих концентрическое строение. Они формируются на горизонтальных и субгоризонтальных поверхностях в условиях постоянного притока материала [17].

В строении кор, сформированных ниже уровня дорожного полотна, часто отмечается выпадение галита (рис. 4, в). Микрокристаллы этого минерала прослоями располагаются внутри древовидных агрегатов (рис. 4,2 ), что соответствует периодам активного использования реагентов на прилегающих улицах. Во всех образцах кор были обнаружены механические примеси в виде городской пыли и разрушенного строительного материала инженерных сооружений, а также силикатные микросреры (рис. $4, \partial, e)$.

Одним из важнейших результатов проведенных исследований является выявление значительной роли живых организмов в развитии городских спелеотерм. Во всех изученных пробах обнаружены гифы грибов (рис. 4, ж, з), выполняющих роль каркаса слоистой структуры и скелета новообразований и, по всей видимости, создающих благоприятные окислительно-восстановительные условия для быстрого осаждения вещества. Кроме того, на поверхностях сферических агрегатов обнаружены многочисленные органические пленки (рис. $4, u$ ), которые являются одним из следов жизнедеятельности бактериальных колоний. Биогенное и хемогенное карбонатообразование соседствуют между собой и отражаются в разнообразии морфологии кристаллов и внутренней структуре новообразований [18-20]. Биогенные процессы, очевидно, предшествуют хемогенным и являются ключевым фактором формирования карбонатных новообразований.

Формирование карбонатных кор является сложным и многостадийным процессом, подверженным сезонным флуктуациям и включающим как хемогенный, так и биогенный пути минералообразования. В общем виде без учета деятельности микроорганизмов данный процесс может быть описан химической реакцией $\mathrm{CaCO}_{3}+\mathrm{H}_{2} \mathrm{O}+\mathrm{CO}_{2}<=>\mathrm{Ca}^{2+}+2 \mathrm{HCO}_{3}^{-}$. На первой стадии, в процессе просачивания дождевых вод через толщу бетонных элементов конструкций, происходит процесс растворения кальцита, содержащегося в связующем веществе цементного камня с образованием $\mathrm{Ca}^{2+}$ и $\mathrm{HCO}_{3}^{-}$. Реакция является обратимой, в частности, при изменении концентрации $\mathrm{CO}_{2}$ относительно ее равновесной концентрации, что и приводит к формированию кор и натеков [21]. Процессы биоминерализации кальцита значительно сложнее, поскольку обусловлены особенностями метаболизма грибов и способом их адаптации к условиям с высокой щёлочностью карбонатов [22-26].

Существует ряд важных особенностей, связанных с условиями формирования карбонатных кор на фасадах зданий. Во-первых, изученные новообразования обнаружены преимущественно на фасадах зданий и сооружений, находящихся в придолинной части города, и, соответственно, формируются в условиях повышенной влажности. Следует подчеркнуть, что карбонатные коры развиваются на фасадах как современных сооружений, построенных менее 5 лет назад, так и зданий, возведенных более 15-20 лет назад. Следовательно, возраст сооружений не является фактором, определяющим возможность развития техногенных спелеотерм. Наиболее интенсивно развитие массивных кор с характерной ячеистой структурой происходит на фасадах набережной, на которых признаки разрушения практически не выражены, в то время как на фасадах более старых частично разрушенных зданий данный процесс заторможен, а значительное количество карбонатного материала цемента выщелочено.

Однозначно установить связь между интенсивностью формирования новообразований и условиями конкретных инженерных сооружений (рас- 
$a / a$

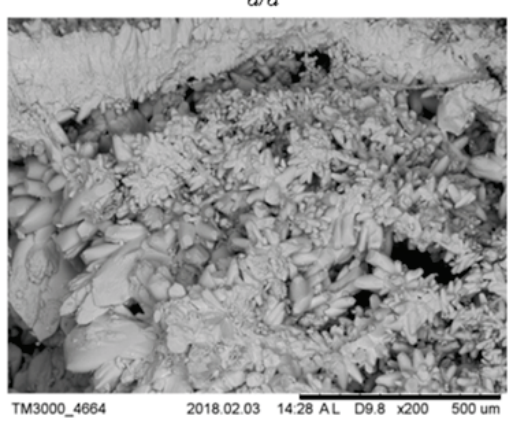

$2 / d$

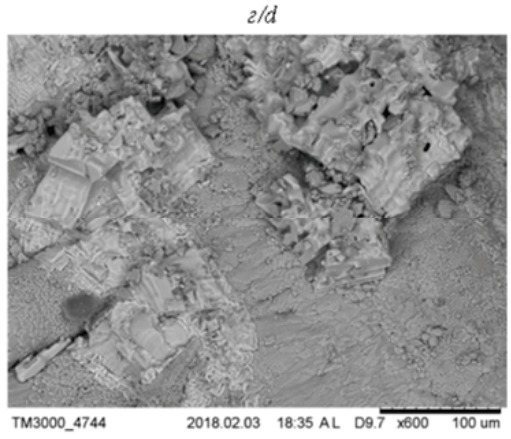

TM3000_4744

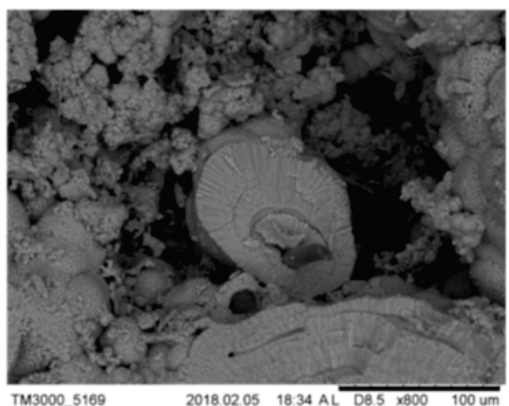

$6 / b$

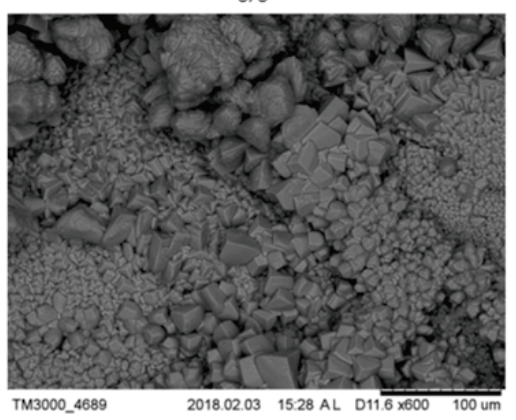

d/e

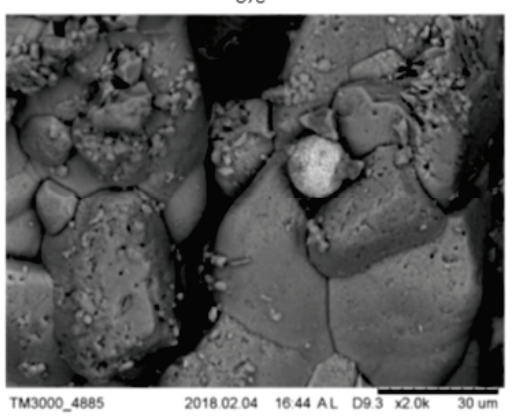

w/g

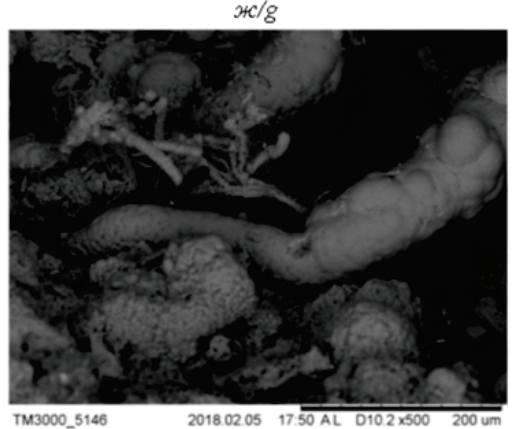

$B / C$

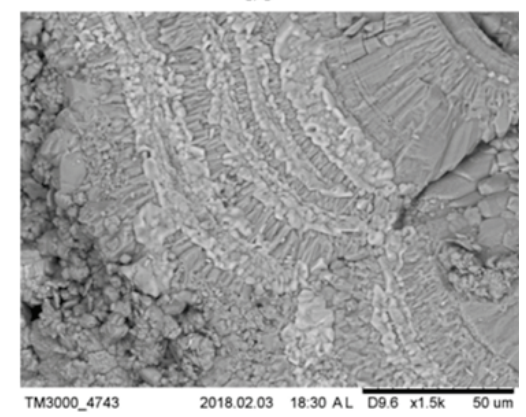

$e / f$

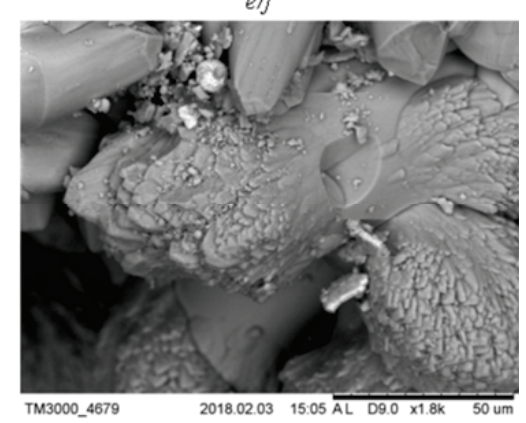

$3 / h$

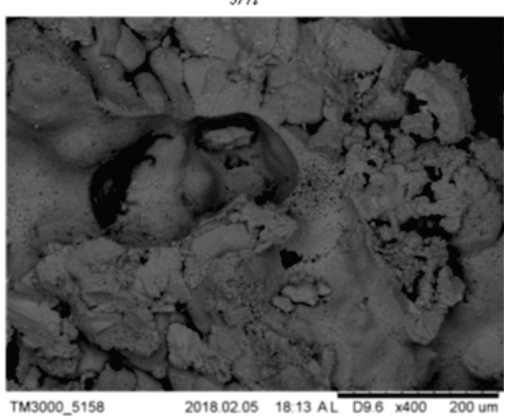

Рис. 4. Элементы микростроения карбонатных кор, сфорлированных на фасадах различных сооружений г. Тюмени, вылвленные при помощи сканирующей электронной микроскопии: а) дендритовидные сростки кальцита; б) сферические ассоциации кальцита; в) отдельные кристаллы галита; г) микрокристаллы галита на поверхности древовидного агрегата; д, е) силикатные микросферы; ж) поперечный срез гифа гриба; з) гиф гриба, выступающий каркасом для новообразований; и) следы бактериальных пленок

Fig. 4. Elements of microstructure of carbonate cores formed on the facades of various structures in Tyumen, identified by SEM: a) dendritic cohesion of calcite; $b$ ) spherical associations of calcite; $c$ ) individual crystals of halite; $d$ ) microcrystals of halite on the surface of a treelike aggregate; $e, f$ ) silicate microspheres; $g$ ) transverse section of fungus hyphae; $h$ ) fungus hyphae protruding as a skeleton for neoplasms; i) traces of bacterial films

положением, особенностями температурного и водного режимов) не представляется возможным, так как все рассматриваемые сооружения отличаются по особенностям конструкций, объему и маркам использованного цемента. При этом можно отметить, что на переувлажнённых участках (нижние уровни набережной) развиваются плотные новообразования с многочисленными признаками биогенного минералообразования. На открытых, хорошо прогреваемых и обдуваемых фасадах южной экспозиции формируются более тонкие коры и натеки, образование которых в большей степени обусловлено хемогенным осаждением карбонатов.

Проведённые исследования свидетельствуют в пользу того, что механическая очистка фасадов не является достаточно эффективным методом пре- дотвращения карбонатообразования. Скорости роста как карбонатных кор, так и менее устойчивых новообразований, таких как сталактиты [9], достаточно высоки. Кроме того, развитие данных новообразований интенсифицируется под воздействием живых организмов - грибов и бактерий. Следовательно, более перспективными являются мероприятия по предотвращению данного процесса, например, герметизация швов, антимикробная обработка поверхностей, а не временная очистка.

\section{Выводы}

Карбонатные коры, сформированные на фасадах различных сооружений г. Тюмени, существенно различаются по особенностям строения, мощности, минеральному составу. Отличия обусловлены 
интенсивностью выщелачивания карбонатного материала, возрастом и конструктивными особенностями конкретных сооружений. Полученные результаты подтверждают высказанные рядом авторов предположения о значительной роли живых организмов, таких как грибы и бактериальные колонии, в формировании техногенных спелеотерм. По всей видимости, именно биогенные процессы превалируют на начальных стадиях карбонатообразования в условиях городской среды и обуславливают скорость их роста. В пустотах, образующихся после формирования основной массы кор, постепенно активизируются процессы хемогенной кристаллизации кальцита. Ключевая роль биогенного осаждения карбонатного материала также

\section{СПИСОК ЛИТЕРАТУРЫ}

1. Tittarelli F., Moriconi G., Bonazza A. Atmospheric deterioration of cement plaster in a building exposed to a urban environment // Journal of Cultural Heritage - 2008. - V. 9. - № 2. - P. 203-206.

2. Amoroso G.G., Fassina V. Stone decay and conservation: atmospheric pollution, cleaning, consolidation and protection. Amsterdam; New York: Elsevier, 1983. - 453 p.

3. An urban geomonumental route focusing on the petrological and decay features of traditional building stones used in Madrid, Spain / E.M. Perez-Monserrat, M.A. de Buergo, M. Gomez-Heras, M.J.V. Muriel, R.F. Gonzalez // Environmental Earth Sciences. 2013. - V. 69. - № 4. - P. 1071-1084.

4. Christaras B. Durability of building stones and weathering of antiquities in Crete/Greece // Bulletin of the International Association of Engineering Geology. - 1991. - V. 44. - P. 17-25.

5. Atmospheric deterioration of ancient and modern hydraulic mortars / C. Sabbioni, G. Zappia, C. Riontino, M.T. Blanco-Varela, J. Aguilera, F. Puertas, K. Van Balen, E.E. Toumbakari // Atmospheric Environment. - 2001. - V. 35. - № 3. - P. 539-548.

6. Török Á. Surface strength and mineralogy of weathering crusts on limestone buildings in Budapest // Building and Environment. - 2003. - V. 38. - № 9-10. - P. 1185-1192.

7. Dow C., Glasser F.P. Calcium carbonate efflorescence on Portland cement and building materials // Cement and Concrete Research. - 2003. - V. 33. - № 1. - P. 147-154.

8. Alves C. «White» Crusts on Recent Buildings // Materials Science Forum. - 2010. - V. 636-637. - P. 1300-1305.

9. Новоселов А.А. Натёчные карбонатные новообразования набережной р. Туры: условия формирования, особенности строения и индикационное значение // Известия Томского политехнического университета. Инжиниринг георесурсов. 2017. - T. 328. - № 4. - C. 46-54.

10. Flores-Colen I., De Brito J., De Freitas V.P. Stains in facades' rendering - Diagnosis and maintenance techniques' classification // Construction and Building Materials. - 2008. - V. 22. - № 3. P. 211-221.

11. Evaluation of cleaning procedures on the facades of the Bank of Greece historical building in the center of Athens / A. Moropoulou, Th. Tsiourva, K. Bisbikou, V. Tsantila, G. Biscontin, G. Longega, M. Groggia, E. Dalaklis, A. Petritaki // Building and Environment. - 2002. - V. 37. - № 7. - P. 753-760.

12. Traffic-related immissions and their impact on historic buildings: implications from a pilot study at two German cities / M. Auras, S. Beer, P. Bundschuh, J. Eichhorn, M. Mach, D. Scheuvens, M. Schorling, J. von Schumann, R. Snethlage, S. Weinbruch // Environmental Earth Sciences. - 2013. V. 69. - № 4. - P. 1135-1147.

13. The effect of air pollution on stone decay: the decay of the Drachenfels trachyte in industrial, urban, and rural environ- косвенно проявляется в морфологии и разнообразии форм кристаллов. Такой механизм формирования новообразований также должен учитываться при планировании мероприятий по очистке фасадов и предотвращению подобных процессов на строящихся объектах и требует дальнейшего изучения.

Полученные результаты свидетельствуют о высокой скорости формирования карбонатных кор и ярко выраженной сезонности данного процесса. Роль биогенных процессов в интенсификации карбонатообрзования является дополнительным аргументом в пользу низкой эффективности механической очистки фасадов, поскольку она направлена на следствие, а не на причину.

ments-a case study of the Cologne, Altenberg and Xanten cathedrals / B. Graue, S. Siegesmund, P. Oyhantcabal, R. Naumann, T. Licha, K. Simon // Environmental Earth Sciences. - 2013. V. 69. - № 4. - P. 1095-1124.

14. Каздым А.А. Природные и техногенные образования кальцита натеки и спелеотермы: генезис, морфология, микростроение // Минералогия техногенеза. - 2007. - Т. 8. - С. 269-287.

15. Каздым А.А., Чижова А.А., Астахов М.И. Техногенные карбонатные новообразования на бетонных покрытиях моста через p. Нерль (Ярославская область) // Минералогия техногенеза. 2005. - T. 6. - C. 32-39.

16. Техногенные спелеотермы / С.С. Потапов, Н.В. Паршина, Н.Г. Максимович, В.А. Наумов // Минералогия техногенеза. 2005. - T. 6. - C. 12-22.

17. Kendall A.C., Broughton P.L. Origin of fabrics in speleothems composed of columnar calcite crystals // Journal of Sedimentary Petrology. - 1978. - V. 48. - № 2. - P. 519-538.

18. Forti P. Biogenic speleothems: an overview // International Journal of Speleology. - 2001. - V. 30. - № 1. - P. 39-56.

19. The biogenic origin of needle fibre calcite / G. Cailleau, E.P. Verrecchia, 0. Braissant, L. Emmanuel // Sedimentology. - 2009. V. 56. - P. 1858-1875.

20. Jones B. Microbes in caves: agents of calcite corrosion and precipitation // Geological Society Special Publication № 336. Tufas and Speleothems: Unravelling the microbial and physical controls. - London: Geological Society, 2010. - P. 7-30.

21. Техногенное отложение биокарбонатов и экспериментальное их образование / Л.В. Леонова, С.С. Потапов, Л.Ю. Кузьмина, О.Я. Червяцова, С.П. Главатских, А.С. Рябова // Минералогия техногенеза. - 2014. - № 15. - С. 113-129.

22. Burford E.P., Hillier S., Gadd G.M. Biomineralization of Fungal Hyphae with Calcite $\left(\mathrm{CaCO}_{3}\right)$ and Calcium Oxalate Mono- and Dihydrate in Carboniferous Limestone Microcosms // Geomicrobiology Journal. - 2006. - V. 23. - № 8. - P. 599-611.

23. Bindschedler S., Cailleau G., Verrecchia E. Role of Fungi in the Biomineralization of Calcite // Minerals. - 2016. - V. 6. - № 2. - P. 41.

24. Interactions of fungi with concrete: Significant importance for bio-based self-healing concrete / J. Luo, X. Chen, J. Crump, H. Zhou, D.G. Davies, G. Zhou, N. Zhang, C. Jin // Construction and Building Materials. - 2018. - V. 164. - P. 275-285.

25. Gadd G.M. Fungi, Rocks, and Minerals // Elements. - 2017. V. 13. - № 3. - P. 171-176.

26. Biogenesis of secondary mycogenic minerals related to wall paintings deterioration process / N. Unković, S. Eric, K. Šarić, M. Stupar, Ž. Savković, S. Stanković, O. Stanojević, I. Dimkić, J. Vukojević, M.L. Grbic̉ // Micron. - 2017. - V. 100. - P. 1-9.

Поступила 05.05.2018 2. 
Информация об авторах

Новоселов $A . A$., аспирант кафедры физической географии и экологии Института наук о Земле Тюменского государственного университета.

Константинов A.O., специалист Научно-образовательного центра «Геология нефти и газа» Тюменского индустриального университета. 
UDC 549.74

\title{
CARBONATE CRUSTS ON FACADES OF BUILDINGS OF TYUMEN: OCCURENCE AND DIVERSITY
}

\author{
Andrey A. Novoselov',
}

mr.andreygeo@mail.ru

\author{
Alexander 0. Konstantinov², \\ konstantinov.alexandr72@gmail.com \\ 1 University of Tyumen, \\ 2, Osipenko Street, Tyumen, 625000, Russia. \\ 2 Tyumen Industrial University, \\ 56, Volodarsky Street, Tyumen, 625000, Russia.
}

Relevance. Carbonate crusts, outgrowths and efflorescences, formed on the facades of various buildings and structures due to components leaching from building materials, such as cement, concrete, limestone, are the most common type of technogenic mineral formation in urban environment. Unlike the unstable stalactites and stalagmites, which are formed only under certain conditions, and the period of existence, as a rule, is limited, such formations are widespread. Development of carbonate crusts, outgrowths and efflorescences on the facades of buildings not only indicates destruction of the bonding components of building structures, but also has a negative impact on aesthetic appeal of urban architecture. Rigid calcite formations fill microcracks and surface irregularities of facing materials, such as granite, which leads to intensification of destruction of natural materials and requires expensive cleaning of facades. Despite the obvious urgency of the problem, there are not many studies devoted to carbonate neoplasms on various buildings and structures.

The main aim of the research is to investigate the peculiarities of mineral composition, structure and possible mechanisms for formation of carbonate cores and filaments generated on the facades of buildings and structures of the city of Tyumen under various conditions, and to identify the factors contributing to this phenomenon.

The methods: identification and systematization of objects of urban architecture subject to formation of carbonate, crusts, outgrowths and efflorescence; study of structural features of the most representative samples of carbonate neoplasms in transparent sections, using scanning electron microscope; determination of gross mineral composition of tumors (X-ray analysis).

The results. The carried out research shown that carbonate cortices and sinters essentially differ in features of structure, mineral structure and probable mechanisms of formation depending on a concrete site. The crusts developing on vertical and horizontal surfaces are clearly divided: the first are flat, thin enough and have a layered structure, the latter are dense and are characterized by a globular structure. Development of carbonate formations probably occurs with significant participation of living organisms. Biogenic and chemogenic processes of calcite precipitation occur synchronically. There are no relationships between the age or location of the studied objects and the intensity of these processes; that is why the constructional particular qualities of buildings and construction materials are the most significant factors.

\section{Key words:}

Carbonate crusts, carbonate neoformations, technogenic speleothems, mineral neoformation, authigenic mineral formation.

\section{REFERENCES}

1. Tittarelli F., Moriconi G., Bonazza A. Atmospheric deterioration of cement plaster in a building exposed to a urban environment. Journal of Cultural Heritage, 2008, vol. 9, no. 2, pp. 203-206.

2. Amoroso G.G., Fassina V. Stone decay and conservation: at mospheric pollution, cleaning, consolidation and protection. Amsterdam; New York, Elsevier, 1983. 453 p.

3. Perez-Monserrat E.M., de Buergo M.A., Gomez-Heras M., Muriel M.J.V., Gonzalez R.F. An urban geomonumental route focusing on the petrological and decay features of traditional building stones used in Madrid, Spain. Environmental Earth Sciences, 2013, vol. 69, no. 4, pp. 1071-1084.

4. Christaras B. Durability of building stones and weathering of antiquities in Crete/Greece. Bulletin of the International Association of Engineering Geology, 1991, vol. 44, no. 1, pp. 17-25.

5. Sabbioni C., Zappia G., Riontino C., Blanco-Varela M.T., Aguilera J., Puertas F., Van Balen K., Toumbakari E.E. Atmospheric deterioration of ancient and modern hydraulic mortars. At mospheric Environment, 2001, vol. 35, no. 3, pp. 539-548.

6. Török Á. Surface strength and mineralogy of weathering crusts on limestone buildings in Budapest. Building and Environment, 2003, vol. 38, no. 9-10, pp. 1185-1192.

7. Dow C., Glasser F.P. Calcium carbonate efflorescence on Portland cement and building materials. Cement and Concrete Research, 2003, vol. 33, no. 1, pp. 147-154.
8. Alves C. «White» Crusts on Recent Buildings. Materials Science Forum, 2010, vol. 636-637, pp. 1300-1305.

9. Novoselov A.A. Singer carbonate technogenic mineral formations of the Tyra river embankment: development conditions, structure features and indication potential. Bulletin of the Tomsk Polytechnic University. Geo Assets Engineering, 2017, vol. 328, no. 4, pp. 46-54. In Rus.

10. Flores-Colen I., de Brito J., de Freitas V.P. Stains in facades' rendering - Diagnosis and maintenance techniques' classification. Construction and Building Materials, 2008, vol. 22, no. 3, pp. 211-221.

11. Moropoulou A., Tsiourva Th., Bisbikou K., Tsantila V., Biscontin G., Longega G., Groggia M., Dalaklis E., Petritaki A. Evaluation of cleaning procedures on the facades of the Bank of Greece historical building in the center of Athens. Building and Environment, 2002, vol. 37, no. 7, pp. 753-760.

12. Auras M., Beer S., Bundschuh P., Eichhorn J., Mach M., Scheuvens D., Schorling M., von Schumann J., Snethlage R., Weinbruch S. Traffic-related immissions and their impact on historic buildings: implications from a pilot study at two German cities. Environmental Earth Sciences, 2013, vol. 69, no. 4, pp. 1135-1147.

13. Graue B., Siegesmund S., Oyhantcabal P., Naumann R., Licha T., Simon K. The effect of air pollution on stone decay: the decay of the Drachenfels trachyte in industrial, urban, and rural environ- 
ments-a case study of the Cologne, Altenberg and Xanten cathedrals. Environmental Earth Sciences, 2013, vol. 69, no. 4, pp. $1095-1124$.

14. Kazdym A.A. Prirodnye i tekhnogennye obrazovaniya kaltsita nateki i speleotemy: genezis, morfologiya, mikrostroenie [Natural and man-made formation of calcite - sinters and shelfstones: genesis, morphology, microstructure]. Mineralogiya tekhnogene$z a, 2007$, vol. 8, pp. 269-287.

15. Kazdym A.A., Chigova A.A., Astachov M.I. New man-caused carbonate formations on the concrete surfaces of the Nerl-river bridge. Mineralogiya tekhnogeneza, 2005, vol. 6, pp. 32-39. In Rus.

16. Potapov S.S., Parshina N.V., Maximovich N.G., Naumov V.A. The technogenic speleothems. Mineralogiya tekhnogeneza, 2005, vol. 6, pp. 12-22. In Rus.

17. Kendall A.C., Broughton P.L. Origin of fabrics in speleothems composed of columnar calcite crystals. Journal of Sedimentary Petrology, 1978, vol. 48, no. 2, pp. 519-538.

18. Forti P. Biogenic speleothems: an overview. International Journal of Speleology, 2001, vol. 30, no. 1, pp. 39-56.

19. Cailleau G., Verrecchia E.P., Braissant O., Emmanuel L. The biogenic origin of needle fibre calcite. Sedimentology, 2009, vol. 56, pp. 1858-1875.

20. Jones B. Microbes in caves: agents of calcite corrosion and precipitation. Geological Society Special Publication № 336. Tufas and Speleothems: Unravelling the microbial and physical controls. London, Geological Society, 2010, pp. 7-30.

21. Leonova L.V., Potapov S.S., Kuz'mina L.Yu., Cherviatsova O.Ya., Glavatskikh S.P., Riabova A.S. The technogenic sediments of biokarbonates and their experimental formation. Mineralogiya tekhnogeneza, 2014, no. 15, pp. 113-129. In Rus.

22. Burford E.P., Hillier S., Gadd G.M. Biomineralization of Fungal Hyphae with Calcite $\left(\mathrm{CaCO}_{3}\right)$ and Calcium Oxalate Mono- and Dihydrate in Carboniferous Limestone Microcosms. Geomicrobiology Journal, 2006, vol. 23, no. 8, pp. 599-611.

23. Bindschedler S., Cailleau G., Verrecchia E. Role of Fungi in the Biomineralization of Calcite. Minerals, 2016, vol. 6, no. 2, pp. 41.

24. Luo J., Chen X., Crump J., Zhou H., Davies D.G., Zhou G., Zhang N., Jin C. Interactions of fungi with concrete: Significant importance for bio-based self-healing concrete. Construction and Building Materials, 2018, vol. 164, pp. 275-285.

25. Gadd G.M. Fungi, Rocks, and Minerals. Elements, 2017, vol. 13, no. 3, pp.171-176.

26. Unkovic N., Eric S., Šaric K., Stupar M., Savkovic Š., Stankovic̉ S., Stanojević O., Dimkić I., Vukojević J., Grbić M.L. Biogenesis of secondary mycogenic minerals related to wall paintings deterioration process. Micron, 2017, vol. 100, pp. 1-9.

Received: 05 May 2018.

\section{Information about the authors}

Andrey A. Novoselov, postgraduate, University of Tyumen.

Alexander O. Konstantinov, specialist, Tyumen Industrial University. 